\title{
AVANCE METODOLÓGICO PARA UNA NUEVA DIVISIÓN DE DISTRITOS EN SEVILLA
}

Gabriel CANO GARCÍA*

\section{RESUMEN}

Se pretende adaptar los criterios de divisiones territoriales, usados en Geografía Regional, a la escala municipal, introducir conceptos y enfoques adecuados (como la delimitación para mejor gestión y desarrollo) y sondear las fuentes posibles para utilizar el máximo de variables convenientes. Entre ellas sobresalen los cambios demográficos, la expansión urbana y sus perspectivas futuras, así como la importancia de los ejes viarios como continentes de los nuevos distritos de Sevilla.

\section{ABSTRAT}

The intention here is to adapt the criteria for territorial divisions, used in Regional Geography, to a municipal level, to introduce appropriate concepts and foci (for example establishing physical boundaries for improved management and development), and to sound out possible data sources in order to use the maximum number of variables. Among these variables, the most significant are demographic changes, past and future urban expansion, together with the importance of the arterial road systems as frame for the new districts in Seville.

\section{INTRODUCCIÓN CONCEPTUAL}

\subsection{Cambios escalares de los criterios delimitadores}

Se trata de exponer una metodología para una nueva división de distritos en Sevilla con límites adecuados, dentro de un trabajo más amplio, en el que se atiende también

\footnotetext{
* Catedrático de Análisis Geográfico Regional. Universidad de Sevilla
} 
(por parte de otros profesores con experiencia investigadora en cada una de las materias) a las competencias en gestión y administración de las Juntas de Distrito; así como a los costes de las remodelaciones. Para quien suscribe, la parte correspondiente del encargo se añade a una serie de publicaciones de divisiones territoriales, siendo la más reciente (año 2002) la dirección de un libro sobre Las Comarcas andaluzas.

Pero la escala es distinta y, en consecuencia, no toda la metodología aplicada en el citado libro servía ahora. Para empezar, las demarcaciones urbanas no son tan antiguas, sino que derivan de la revolución industrial, que trae, entre otros corolarios, las primeras concepciones de planificación y ordenación del territorio en unas ciudades cada vez más pobladas y complejas (éxodo rural, fábricas, barrios obreros, congestión de tráfico...). Y, aunque a Sevilla apenas llegó la industrialización, no fue excepción en muchas de sus consecuencias; y en el caso que nos ocupa, poco antes de la demolición de las murallas almohades (de la que restan los lienzos de la Macarena y otros) se abordó la división del término municipal, cuyos primeros distritos aparecen en 1863.

Si hacemos un rápido recorrido por los principales criterios identificadores usados más frecuentemente en Geografía Regional (disciplina que tiene precisamente buena parte de sus contenidos en la consideración del territorio a distintas escalas, interrelacionando los diferentes factores y elementos), notaremos diferencias y matices escalares. La región natural (primer criterio en una época naturalista, de economía rural y fuerte peso del medio, hasta llegar al determinismo), que utiliza como factores relieve, clima, vegetación, cuencas hidrográficas, etc., vale menos para distritos municipales. En Sevilla, la escasa elevación y desnivel (poco más que la denominación del Cerro del Águila) no introducen elementos de delimitación; en cambio, los ríos sí cuentan como separadores: es el caso del Guadalquivir y alguno de sus afluentes (Tamarguillo, Tagarete...).

El concepto de territorio histórico (tan utilizado a escalas amplias, especialmente de países o comunidades autónomas) también vale a nivel municipal. Porque Sevilla, al igual que otras ciudades andaluzas (Granada, Córdoba, Málaga, por ejemplo), parten de un importante núcleo islámico medieval amurallado, que ha permanecido durante siglos, al que se insertaban caminos radiales que articulan luego un crecimiento urbano. Esa estructura condiciona unas divisiones de sectores más o menos circulares, a la vez que marcan con identidades acusadas barrios antiguos, si bien las expansiones recientes adolecen de esas características.

El criterio de homogeneidad está menos estudiado, pero tiene sus ventajas en la territorialización (CANO, 1990) e introduce una interesante controversia homogeneidad heterogeneidad socioeconómica en barrios y distritos, a la que nos referiremos. La funcionalidad es el criterio más utilizado ahora en la delimitación y responde a una realidad moderna, como es la existencia de un centro (ciudad, metrópolis, conurbación...), que ofrece bienes, servicios, trabajo, residencia, información... 
a un área más o menos extensa y con enlaces densos y rápidos. Indudablemente las zonas de influencia pueden ser muy amplias para determinadas cosas (por ejemplo, Bruselas en la Unión Europea), pero son las áreas metropolitanas y, en parte, las comarcas, los mejores exponentes de esta funcionalidad en trama de interrelaciones diarias y cambiantes; en las que progresivamente las residencias se desplazan a la periferia. A escala municipal es más difícil definir un mapa de distritos mediante la acción de centros, aunque en el caso de Sevilla, además del casco histórico, podemos encontrar alguno, como Nervión, cada vez más potente, y otros menos definidos, como los Remedios.

La llamada región plan es otro tipo de espacio, consistente en la demarcación utilizada principalmente en terrenos de implantación reciente con ausencia de identidades geográficas, históricas o culturales. En este sentido MARCHENA y LÓPEZ, 1986, distinguen en la experiencia europea de distintas ciudades tres tendencias: circunscripciones electorales, reconocimiento de entidades o límites administrativos para la gestión, más o menos mezcladas, resultando un mayor peso de la segunda opción cuando se pretenden funciones consultivas. Y, a la vista de algunos estudios (Madrid, Barcelona, Valencia, Bilbao, Zaragoza y Córdoba), detectan un predominio de distritos grandes en relación con las funciones de participación.

El criterio administrativo debe valorarse a escala municipal, a fin de un máximo de coincidencia entre diferentes demarcaciones sectoriales (postales, fiscales, censales, de salud...) en beneficio de la mejor gestión y comodidad de los ciudadano; teniendo especial cuidado con las secciones censales (siempre que no alteren barrios tradicionales) que son unidades estadísticas demográficas, fundamentales para cualquier estudio. Claro que al definir distritos se puede pretender que todos los demás límites se acomoden, lo que no siempre es viable; será útil un grado de equilibrio.

Comparando una vez más con otras escalas, concretamente con la comarcal, hay un criterio, cual es la articulación de espacios periféricos (CANO, 2001), que tendremos en cuenta aquí, en relación con el enfoque de enmarcar para desarrollar. En fin, más adelante se plantean criterios demográficos, modificaciones urbanas, límites varios, centros y ejes, aspectos económicos, culturales, sociales, de participación, etc., que se utilizarán en este trabajo y que pueden insertarse en los grandes bloque apuntados antes de homogeneidad, funcionalidad, historia...

\subsection{Los marcos territoriales para la gestión y el desarrollo}

Establecer circunscripciones territoriales no es sólo una operación técnica basada en la acumulación de información (si bien esta misma investigación supone ya un bagaje metodológico y de criterios para orientar la búsqueda y obtener provecho de lo conseguido), sino que hace falta algo más: teorías, planteamientos, conceptos..., 
como hemos visto. Y, además, circunscribir espacios para una mejor gestión y participación ciudadana, como es el caso de los distritos municipales, trasciende lo territorial para adquirir consecuencias sociales, económicas y de otro tipo.

Y en ese sentido, conviene remarcar aquí la importancia de las delimitaciones como gestión y desarrollo, porque los límites y las fronteras han tenido, y tienen todavía, una parte negativa de exclusiones, marginaciones, polémicas o luchas. Enmarcar hoy territorios a diferentes escalas (concretamente a la urbana en esta ocasión) debe plantearse con el enfoque positivo de reconocimiento espacial para el desarrollo, la calidad de vida y la racionalización de inversiones, instalaciones y actuaciones públicas, que, a su vez, influyan en acciones privadas y empresariales. Una de las metas del nuevo Plan General de Ordenación Urbana (2001) es precisamente el barrio y el barrio-ciudad como unidad de intervención, por lo que "la gestión centralizada de los equipamientos no garantiza su utilidad" (p. 77). Reconocer un espacio, delimitarlo, denominarlo y proveerlo de determinados funcionamientos de gestión y participación ciudadana es una operación de alto valor, porque lo introduce en el circuito de proyectos, presupuestos e inversiones. $\mathrm{Si}$, por ejemplo, la parte norte de Macarena (San Jerónimo, pino Montano, etc.) tuviese un reconocimiento territorial y se convirtiese en distrito, sería cada vez más atendido y menos periferia, al menos en equipamientos e infraestructuras.

La división en distritos urbanos puede contribuir a todo eso, por lo que una buena distribución de los mismos se convierte en factor importante de la vida ciudadana, y conviene adelantar algunas ideas o planteamientos básicos. Uno es el contenido administrativo, político, social... de los distritos, cuestión que se aborda en otra parte de este trabajo desde el enfoque del Derecho administrativo. A efectos de divisiones, existen múltiples posibilidades entre, por un lado, no ir mucho más allá de unas denominaciones y cartografías hasta, por otro, convertir los distritos en una especie de pequeñas ciudades.

Sin embargo, hay que estudiar detenidamente lo que a veces se denomina " una ciudad de ciudades" en las divisiones distritales, porque, si bien puede suponer un elevado grado de desconcentración, también conlleva algunos riesgos. La excesiva especialización zonal con ciudades universitaria, de justicia, del comercio, transporte, etc. tiende a despoblar de residencias algunos de esos espacios, generando complicaciones y mayores costes en infraestructuras y desplazamientos, aparte de los deterioros en el paisaje humano en ciertas horas y días.

Por otra parte, parecen elementos mínimos indispensables la consideración de espacios amplios (pero englobando barrios sin romperlos), con identidad, funcionalidad, representatividad, participación, desconcentración de funciones (teniendo en cuenta unos costes razonables, lo que se estudia en el bloque tercero desde la Economía) y coordinación en el conjunto municipal con eficacia administrativa. Si el número de distritos fuese excesivo su puesta en marcha y funcionamiento sería más difícil. 
Otro asunto que interesa adelantar es la controversia homogeneidad heterogeneidad, especialmente en lo relativo a las características socioeconómicas. La segregación en una especie de guetos, de un lado, y barrios de alta residencia, por otro, no es lo más adecuado; pero una determinada mezcla puede enmascarar actuaciones y convertir en minorías territoriales y sociales a los barrios más deprimidos. Habrá que ver las situaciones concretas para definir distritos según esa doble cautela.

Por último, los límites deberían ser puntos de referencia claros, sabiendo que no apartan, sino que unen barrios más o menos similares en orden a los objetivos mencionados; y que esos marcos no separan estructuras diferentes, sino que todos los distritos han de tener las mismas funciones y competencias. Partir en el análisis de las circunscripciones actuales, conlleva utilizar una serie de criterios que detecten los cambios habidos desde finales de los ochenta para proponer las oportunas modificaciones. De manera que empezaremos por lo más evidente, aumento de población y de la edificación en cada distrito, así como de los proyectos de expansión urbana y otros criterios (económicos, sociales, culturales, de centros y comunicaciones, etc.). Pero antes conviene recordar las divisiones urbanas anteriores, cuyos precedentes se hallan en 1863.

\section{EVOLUCIÓN DE LOS DISTRITOS Y BARRIOS SEVILLANOS}

\subsection{Los distritos desde 1863}

Efectivamente antes de estudiar la necesidad de una nueva división distrital de Sevilla, conviene saber cuales y cómo han sido éstas a lo largo del tiempo; tanto por presentar una información más completa, como, y sobre todo, por conocer los criterios utilizados y valorarlos ahora tras saber sus resultados. Así analizaremos los primeros distritos de 1863 y los de 1970 (estudiados por MARTín,1986), y prestaremos especial atención a los actuales, porque no partimos de cero en la propuesta que hagamos, sino de una división existente, que, pasados veinte años, conviene, eso sí, remodelar y modificar.

En realidad, existe una experiencia, con luces y sombras, que es menester analizar con detalle, pero ahora proceden algunos avances metodológicos. La primera demarcación se realiza en 1863, en una época, como dijimos, en que las ciudades (no tanto Sevilla) traspasan los límites tradicionales y se acumulan servicios y gestiones que se intentan desconcentrar. Esa primera acción consta de diez territorios a efectos fiscales, electorales, de empadronamiento, policía municipal... (MARTíN, 1986), pero la mitad en el casco histórico, que, además de Triana, era prácticamente lo único existente. 
Pues fuera de las murallas se situaban; al norte un pequeño barrio de la Macarena con el Hospital de las Cinco llagas; al nordeste la Fábrica de salitre y el barrio de San Roque, próximos a ambos lados de Puerta Osario; desde la Puerta de Carmona a la Cruz del Campo estaban, el convento de San Agustín y los también reducidos barrios de San Bernardo y San Benito; entre éstos y la actual Ramón y Cajal, instalaciones militares (cuartel, Fundición de artillería, Pirotecnia...); y al sur de la calle San Fernando sólo la fábrica de Tabacos, actual Universidad, el palacio de San Telmo y un desaparecido convento de San Diego (hoy glorieta); al oeste, Carretería, Cestería, la Maestranza, San Laureano y el barrio de los Humeros entre la muralla y el Guadalquivir. No fueron los únicos elementos de división, ya que operaron también las carreteras de Carmona y Alcalá para enmarcar los distritos II, IX y X; pero, con todo, las parcelaciones periféricas apenas tenían población y no se respetó siempre el principio de continuidad espacial.

Durante un siglo se mantuvo la división anterior, a pesar del aumento poblacional y de una cierta expansión urbana carente de planificación (Exposición del 29 y sus consecuencias, barrios obreros, alguno muy en precario como Amate, Nervión, Heliópolis...). Diversas leyes locales de los años cincuenta del siglo XX llevaron a la reconsideración de los distritos municipales, aprobados el 28 de febrero de 1968 en el Ayuntamiento, pero no por el Ministerio de la Gobernación hasta julio de 1970.

Sigue el número de diez, aunque sólo dos en el casco antiguo y el extenso distrito segundo de 1863 (desde Luís Montoto por todo el centro-sur hasta la dársena) se subdivide en cuatro partes, además de otros retoques en los límites y la inclusión de algunas figuras legales, que pretendían (aunque no se llevan a efecto) cauces de representación y participación: delegados de distritos, alcaldes de barrio, Juntas de delegados, Consejos ciudadanos y oficinas municipales.

Tras el cambio de Régimen y la democratización, Sevilla aborda una reestructuración de su espacio municipal, que había pasado de poco más de 550.000 habitantes en 1970 a superar los 700.000 a finales de los ochenta con la consiguiente expansión urbana (como consecuencia también del abandono de parte del centro histórico) y las modificaciones poblacionales. El distrito I (mitad norte del casco histórico) había perdido en un cuarto de siglo casi cien mil habitantes y, por el contrario, el V (prácticamente la demarcación Sur actual) ganó en ese mismo período 40.000; Nervión (VI), unos cincuenta mil y las zonas periféricas del este y el norte (distritos VIII, IX y X) pasan de 85.000 a casi 300.000 .

Entre otras razones, la necesidad del cambio se basaba en la desigualdad demográfica de los diez distritos existentes, límites artificiales no acordes con realidades sociales o históricas, desajustes con divisiones sectoriales y conexión con el ámbito metropolitano. Los criterios y objetivos apuntaban a la desconcentración de funciones y desarrollo de la participación ciudadana, sin un coste que imposibilitara el proceso (lo que explicaría la reducción del número de distritos), con una cierta diversidad 
social y urbana en orden a reequilibrios y redistribución interna. El Reglamento de las Juntas Municipales de Distrito de noviembre de 1986 constituía buena parte de la base legal y un extenso trabajo de Geografía Regional, elaborado por los profesores M. MARCHENA y E. LÓPEZ en 1988, por encargo del Área de Participación Ciudadana, constituyó la base de esta remodelación de 1989.

\subsection{Importancia y problemática de los barrios}

Aunque no es propósito del estudio presente una propuesta de división en barrios de Sevilla, sí es cuestión fundamental que los límites de los distritos que se propongan no rompan sobre el mapa las entidades más pequeñas de barrios, barriadas, etc. Es decir, pretendemos mantener esas unidades y, en consecuencia, hemos de analizar su situación, especialmente las referidas a las zonas limítrofes; sin embargo, veremos la dificultad existente, al haber divisiones de distintos resultados.

Hay varios estudios sobre la definición de barrio; por ejemplo dos recientes. Desde la Geografía, MULERO, 1988, dedica unas páginas a esta unidad de análisis como la más generalizada concepción urbana entre la calle y la ciudad, aunque reconoce la dificultad de su conceptualización, que después sistematiza en varios puntos (geográfico, arquitectónico-urbanístico, sociológico, histórico) para plantear los criterios básicos de delimitación. Insiste en la variedad de matices de una ciudad tan rica como Córdoba (ampliable a Sevilla u otras ciudades andaluzas) y la necesidad, por lo tanto, de aplicar diversos criterios (morfológico, funcional, vivencial, socioeconómico, emplazamiento, excentricidad, límites, denominación y etnia) para dividir en 44 barrios con su población, enmarque y superficie desde los 25.000 habitantes a los 945 y desde 560 Ha a 3.65 .

El otro estudio que tendremos en cuenta está dirigido por el catedrático de Antropología Social, Dr. MORENO, 2001, donde se conceptualizan bien los barrios y se designan en Sevilla "aquellos territorios que...posean características situaciones, morfológicas, sociales, históricas y simbólicas que los doten de una personalidad autopercibida por sus habitantes y/o percibida por los habitantes de otros lugares de la ciudad" (p. 13). Incluye en la relación urbanizaciones o núcleos residenciales como barrios potenciales en una consideración dinámica, que le lleva a proponer también unidades inferiores (subbarrios y zonas) y otra superior, el sector, entre barrio y distrito. Los criterios son múltiples: denominación, límites físicos y simbólicos, homogeneidad, heterogeneidad, origen y evolución, tipos de urbanismo, equipamientos, servicios, funciones, actividades, asociacionismo, referentes simbólicos...Y conduce a una propuesta concreta, que después mencionaremos.

Antes introducimos, para conocimiento de fuentes y criterios, la evolución de divisiones desde la administración de barrios u otros territorios similares o más 
pequeños, que, en general, adolecen de bastante indefinición. Tal ocurre en las delimitaciones anteriores a 1992, como las de 1971 (más de 80 barrios se dice) como base, pero se modifican haciendo hincapié en la sección censal como célula, "intentando hacerlas coincidir con el espacio geográfico que constituyen cada barrio natural". Y se consideran las actuaciones del Servicio de Estadística, las Áreas homogéneas de urbanismo (que encierran, a su vez, subdivisiones) y, para el casco histórico, las divisiones parroquiales, resultando tres propuestas.

\section{CUADRO 1.}

\section{NÚMERO DE DIVISIONES INTRADISTRITOS}

\begin{tabular}{|l|c|c|c|c|c|c|c|}
\hline \multirow{2}{*}{ DISTRITOS } & \multicolumn{4}{|c|}{ AÑO 1992 } & \multicolumn{3}{c|}{ ACTUALES } \\
\cline { 2 - 8 } & $\begin{array}{c}\text { Partici- } \\
\text { pación } \\
\text { Ciudadana }\end{array}$ & $\begin{array}{c}\text { Esta- } \\
\text { dística }\end{array}$ & $\begin{array}{c}\text { Agencia } \\
\text { Urbanismo }\end{array}$ & Boletines & $\begin{array}{c}\text { Gerencia } \\
\text { Urbanis- } \\
\text { mo, 1994 }\end{array}$ & $\begin{array}{c}\text { Secciones } \\
\text { Censales }\end{array}$ \\
\hline Casco antiguo & 10 & 10 & 2 & 35 & 10 & 11 & 53 \\
\hline Macarena & 25 & 31 & 5 & 35 & 38 & 24 & 112 \\
\hline Nervión-San Pablo & 18 & 21 & 5 & 25 & 19 & 16 & 88 \\
\hline Este & 11 & 14 & 5 & 17 & 12 & 18 & 115 \\
\hline Sur & 16 & 15 & 7 & 28 & 20 & 21 & 82 \\
\hline Triana-Los Remedios & $5 *$ & 7 & 4 & 49 & 7 & 10 & 62 \\
\hline \multicolumn{1}{c|}{ TOTAL } & 85 & 98 & $28^{* *}$ & 152 & 106 & 100 & 512 \\
\hline
\end{tabular}

Fuente: Elaboración propia a partir de las fuentes y bibliografía citada

Notas: * Se insinúa un sexto barrio de Cartuja

** Estas 28 áreas comprenden 152 unidades inferiores ("barrios", "barriadas", "urbanizaciones"), que son las cifras segunda de cada casilla

Ahora nos encontramos con una multiplicidad de parcelaciones inferiores al distrito y se utilizan al menos dos divisiones en barrios de manera más o menos oficial. Por un lado los 106 (que a su vez en alguna cartografía se subdividen en 512 secciones censales), que aparecen en tablas y mapas de publicaciones estadísticas, cuyas informaciones y datos hemos de utilizar (Boletín demográfico de la ciudad de Sevilla o Anuarios estadísticos). Por otro, las 100 demarcaciones realizadas en 1994 por la Gerencia de Urbanismo, que es prácticamente la del área de Economía y Turismo del Ayuntamiento, y que hemos seguido en el Atlas Cultural del Municipio de Sevilla (CANO, 2002-b), porque, aun siendo mejorables, nos parecían más adecuadas. Y, aunque el número final no es muy distinto (como se ve, en torno a la centena), existen apreciables diferencias. Así, por ejemplo, en la primera clasificación referida se 


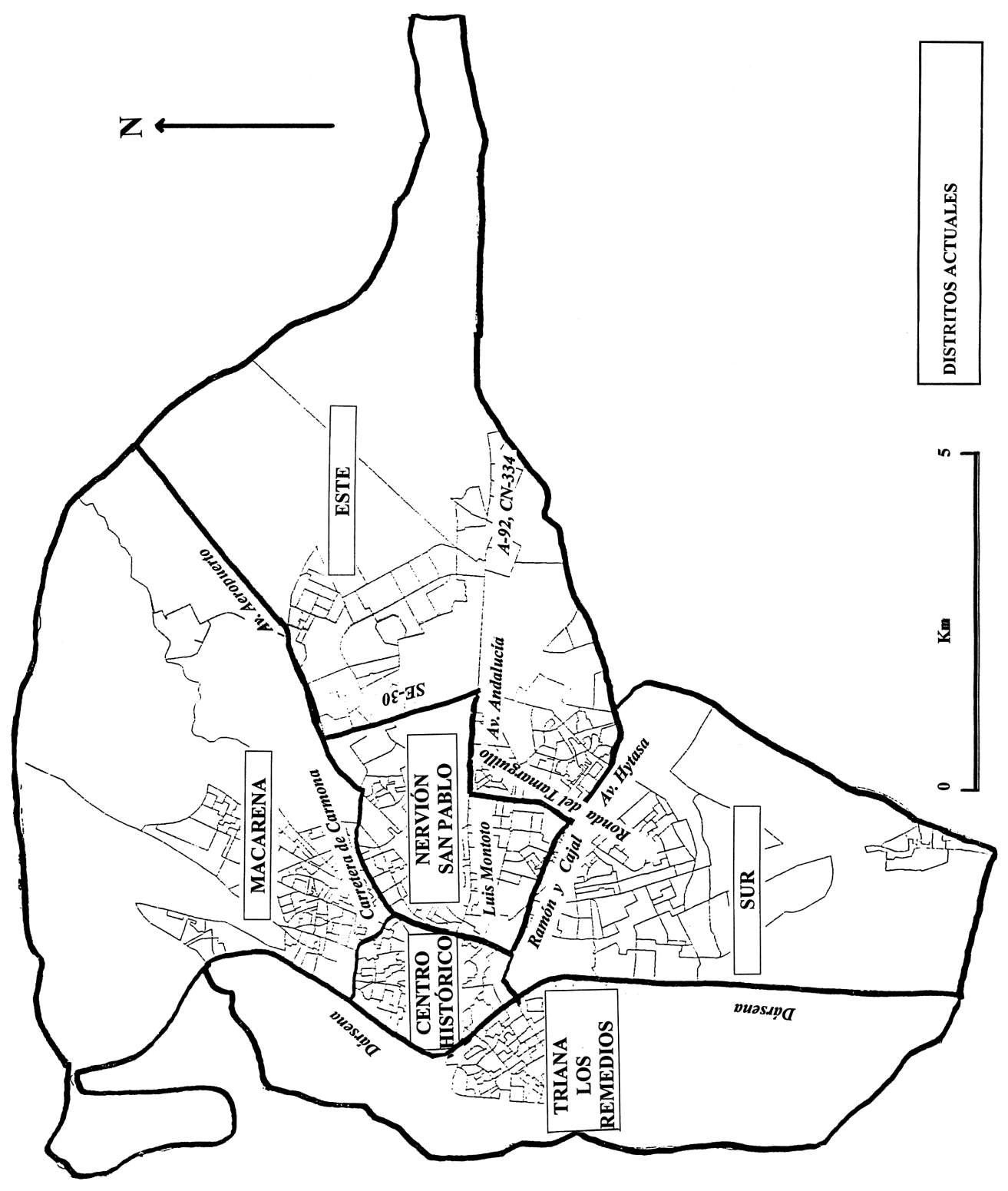


agrupan Plaza de Armas y San Vicente en un solo barrio y en la Macarena se fracciona excesivamente la parte más próxima a la Ronda, mientras se hace un solo apartado con "Nuevo Parque, Aeropuerto Viejo, Polígono Calonge". En el Este no aparecen entidades como Andalucía Residencial, Palacio de Congresos o Entreparques; ni Turruñuelo o Patrocinio en Triana.

De manera que, aunque, como dijimos, no es el objetivo de este trabajo llevar a cabo una remodelación de barrios, este territorio supondrá la unidad mínima de análisis para la propuesta final. Contamos con alguna información y criterios, especialmente las tres mencionadas (que llamaremos estadística, urbanística y antropológica), además de la división censal, siempre que sea posible mantener.

\section{IDENTIFICACIÓN TERRITORIAL}

Analizada la evolución de los distritos en Sevilla (y, claro, de forma detallada la actual división) y advertida la importancia de los barrios, conviene abrir un apartado acerca de cómo se identifican unos y otros para tener unas ciertas ideas previas, partiendo de lo que existe para transformarlo. Porque es necesario conocer lo que es aceptado e identificado, sabiendo que las divisiones territoriales, incluso las no muy adaptadas a la realidad (por otra parte distinta según ciencias y enfoques) acaban por crear costumbres, intereses y aceptaciones; y, como mínimo, están siendo desde hace quince años la desagregación territorial utilizada en estudios, informes, estadísticas, planificaciones, proyectos, etc. El método en este avance del trabajo será en principio una visión general de cada distrito, atendiendo a continentes y contenidos.

La dársena es una clara frontera, mayor que la distancia real, lo que sucede en todas las ciudades con río, que además, como es el caso de Sevilla, suelen tener orígenes distintos en ambas orillas. El actual distrito Triana-Los Remedios alberga ya en su denominación una dualidad de génesis, evolutiva, socioeconómica e identitaria, que el tiempo tiende a disminuir. Máxime con la aparición de barrios más recientes a la Triana tradicional (bastante transformada ya), como el Tardón hacia el muro de defensa y, por supuesto, toda la zona nueva de la Cartuja, aunque se trate de espacio no residencial. Y a este propósito convendría considerar que los distritos tienen una finalidad principal ligada a la gestión y participación ciudadana, pero, también, como ámbitos de organización, planificación y desarrollo..

Tal cuestión nos llevaría a que, a pesar de existir esa frontera real y sicológica del río, la Cartuja podría estar ligada al centro, aunque en principio no parece lo mejor; habrá que estudiarlo bien. Y algo similar cabría decir entre las orillas de los Remedios y avenida de la Raza, precisamente en la zona portuaria industrial entre los puentes de las Delicias y Quinto Centenario. Los Remedios ha crecido menos, constreñido por el parque de los Príncipes, los terrenos de la Feria y las instalaciones 
de Tablada, pero, como veremos después, hay posibilidades y proyectos de grandes modificaciones; en cualquier caso, son dos espacios bien diferenciados e identificados como distintos en el distrito. Y, aunque se estudien otras alternativas, la Dársena constituye un límite claro, como también lo es, yendo por la Puerta de Jerez, el puente de San Telmo, desde donde se vislumbran las dos unidades, Triana y Los Remedios, en la plaza de Cuba y por República Argentina.

El centro histórico es un espacio nítidamente percibido con unos contenidos de bastante homogeneidad, lo que no anula la aplicación de distintas variables, que singularicen y aconsejen algún cambio en la delimitación, aunque la Ronda es un viario bastante aceptado y aceptable de momento. Nervión-San Pablo (también se encierra la dualidad en el nombre) es un espacio muy transformado (estación de Santa Justa, antiguos cuarteles...) y no acabado aún por las posibilidades que ofrecen terrenos industriales. Se trata de una zona nueva de la ciudad, cada vez más centro urbano y con ciertos espacios de calidad, donde la identificación de Nervión es evidente; si bien, la otra parte, el Polígono San Pablo, adolece de muchas carencias $\mathrm{y}$, desde luego, es bastante distinto en tantas cosas (arquitectura, economía, calidad de vida...) a Santa Clara. Veremos los resultados del estudio, que deberá proponer posible división de las dos partes denominadas, la linde entre ellas y, si siguen siendo válidos, como parece en principio los límites externos actuales.

Nadie duda, por otra parte, de la identidad del espacio Macarena, antiguo arrabal extramuros que ha ido creciendo en barrios abigarrados hacia el norte, pero el distrito abarca ya mucho más que eso. Hasta la circunvalación SE-30 se ubica un ámbito más denso desde las Murallas y la Ronda con transformaciones al oeste (Torre Don Fadrique, Nuevo Torneo) y edificaciones algo más abiertas al este (San Diego, las Naciones). El parque de Miraflores alivia la congestión y los polígonos industriales (Calonge y Store), encierran probables nuevos usos del suelo. Más allá de la SE-30 hay un espacio urbanizado muy identificado (San Jerónimo, Pino Montano) y al este amplios terrenos con algún barrio alejado, como Valdezorras. Es decir, este distrito reclama una atención especial en las propuestas, tanto en los límites actuales, (aunque la carretera de Carmona y la avenida de Kansas City-Aeropuerto tienen consistencia), como en la subdivisión interior en cuanto a número de demarcaciones y delimitación entre ellas.

Algo parecido sucede con el Este, nombre sugeridor de escasa identidad (igual que cuando a Macarena se le llama Norte, sobre todo por la zona mas reciente), aunque hace referencia a un espacio nuevo lleno de urbanizaciones con la marca Sevilla Este, mezclada con la de Aeropuerto. Es un área de urbanizaciones y proyectos, que engloba dos barriadas de fuerte identidad, Parque Alcosa y Torreblanca. Pero contiene así mismo un conjunto de barrios abigarrados de fuertes singularidades (Los Pájaros, Candelaria, Rochelambert, Amate, Juan XXIII, Cerro del Águila...), aunque carente de identificación global, como no sea la delimitación en un cuadrilátero entre 
importantes ejes de tradición o actualidad delimitadora: Ronda del Tamarguillo, Avenida Andalucía, SE-30, Avenida de Hytasa. De nuevo, posibilidades de divisiones con establecimientos de límites, sin descartar revisiones de los actuales.

Sobre todo el que linda con el Sur, ya que la separación de los polígonos junto a Hytasa del Cerro del Águila puede ser discutible; incluso ese eje de larga trayectoria fronteriza, que llega al centro por Ramón y Cajal y la Enramadilla, se ha modificado bastante en la confluencia con otros dos distritos, Nervión (zona de Viapol, desaparecido cuartel de Cuatro Vientos) y Centro (el Prado, Universidad...).

Es decir, habrá que estudiar el límite septentrional del distrito Sur, que en los otros lados son la frontera municipal y la Dársena. Los contenidos de esta demarcación meridional son más heterogéneos que en los demás y entre la avenida de la Palmera y las Tres Mil viviendas, por ejemplo, hay todas las diferencias: arquitectónicas, urbanísticas, de equipamientos, económicas...Y se nota más que en los otros ámbitos periféricos una doble tendencia: por un lado la alineación longitudinal en torno a ejes viarios, que, a su vez, articulan (salida a carretera de Cádiz) o separan (ferrocarril, aun en la parte soterrada). Y, en segundo lugar, se organizan bandas transversales, que, por una parte, unen al centro en múltiples aspectos (Universidad, San Telmo, parque de María Luisa, Porvenir) y, por otra, marca el Polígono Sur, que parece va a ser más atendido por las administraciones públicas. Por si faltara algo, se proyecta especializar más aún la función hospitalaria y en el extremo del distrito, un barrio muy identificado, Bellavista, pero con poca población.

Vemos, pues, en esta preparación de fuentes y métodos (donde es menester un cierto conocimiento del espacio objetos de estudio), que, aun partiendo de lo actual, se nota la necesidad de una remodelación de distritos, para lo que precisaremos un bagaje de criterios, factores y elementos; tantos como sean posibles en el presupuesto temporal. Y sin desconocer las diferentes valoraciones de cada uno, para evitar un conjunto indiscriminado, confuso y poco útil; por el contrario, seguiremos un orden de prioridades y procuraremos en cada caso calibrar importancias. Por eso empezaremos con los crecimientos demográficos y la expansión urbana, no sin antes alguna referencia al ritmo de las modificaciones distritales recientes.

\section{CRITERIOS Y FACTORES DE UNA REMODELACIÓN DE DISTRITOS}

Hace trece años de la última división y, si consideramos que el estudio previo es de 1986, nos colocamos en un período de 16 años, que son justamente los que median entre la última fecha citada y 1970, en que se instituyeron los diez distritos anteriores a éstos. Es decir, estaríamos en las fechas esperadas para modificar, según los antecedentes $\mathrm{y}$, aunque los cambios demográficos no son grandes ni generalizados, al menos en cantidad, sí que hay modificaciones y, sobre todo, nuevos espacios ocupados 
y otros urbanizables. Por eso, abordamos en primer lugar dos factores importantes, cuales son la población y la expansión urbana desde finales de los ochenta, más los proyectos de uso de terrenos periféricos, que atañen a todos los distritos actuales, salvo el centro y, en menor medida, Nervión. Se trata de adelantar criterios, factores, elementos, conceptos, métodos, técnicas..., que vamos a utilizar en la investigación; ya iniciada, al menos en la preparación del trabajo, el manejo de fuentes y bibliografía, que posibilita realizar un resumen de cómo está el estudio en estos momentos.

\subsection{La población}

Dado que la remodelación de distritos va dirigida a la mejor gestión y participación ciudadana, es indudable que las características y los cambios demográficos han de ser un factor relevante de la propuesta y así se entiende en la mayor parte de la bibliografía manejada. Por eso, lo primero que veremos es la distribución de población por distritos, comparando con la de 1986, y las superficies, tal y como tenemos preparado en la tabla siguiente.

Una primera apreciación es que la diferencia actual entre distritos (126.845) sobrepasa la de 1986 (86.733) y se acerca a la existente en 1970, precisamente por el crecimiento del sector Este y el estancamiento del menos poblado, el Casco histórico, con algo más de los cincuenta mil. De tal manera que el primero (con la cuarta parte de los efectivos municipales) triplica al segundo (apenas el $8 \%$ ); cuando en 1986 la ratio era de 2.5. Sin embargo, las disparidades de población entre distritos es algo bastante frecuente en otras ciudades, tanto andaluzas, como estatales y de diferentes países, de las que estamos recabando información. A fin de obtener un cierto módulo, semejante a otros lugares con planteamientos similares de mejora social y participativa y, también, que evite en lo posible la existencia de circunscripciones heterogéneas en la cantidad de habitantes. Y, aunque el aumento desde 1986 no sobrepasa mucho los 50.000 en el municipio, en algunos distritos el incremento es alto, casi cuarenta mil en el Este.

Pero no basta con la cantidad, es menester analizar las estructuras, al menos en tres parámetros, sobre los que existe información (Boletines demográficos): densidad de población, envejecimiento y características socioeconómicas, dentro de lo que podemos considerar el criterio de homogeneidad/heterogeneidad. La densidad de población, dice mucho de esas condiciones de disparidad de rentas y, claro, influye sobremanera en la extensión y delimitación de espacios. También las reflejan y aprovecharemos, así mismo, las cifras de envejecimiento y de población inmigrada y extranjera, que por distintas razones precisan atenciones especiales de la administración. 
CUADRO 2.

POBLACIÓN 1986-2001 POR DISTRITOS ACTUALES

\begin{tabular}{|c|c|c|c|c|c|}
\hline Distrito & $\begin{array}{c}\text { Población } \\
\text { 1986* }\end{array}$ & $\%$ & $\begin{array}{c}\text { Población } \\
\text { 2003** }\end{array}$ & $\%$ & $\begin{array}{c}\% \text { Superficie } \\
\text { Municipal }\end{array}$ \\
\hline Casco Antiguo & 55.552 & 8.48 & 56.804 & 7.96 & 2.8 \\
\hline Macarena & 142.285 & 21.77 & 156.532 & 21.95 & 29.5 \\
\hline Nervión- San Pablo & 127.746 & 19.54 & 122.327 & 17.14 & 6.2 \\
\hline Este & 134.412 & 20.55 & 183.649 & 25.75 & 27.0 \\
\hline Sur & 107.569 & 16.45 & 112.716 & 15.80 & 17.8 \\
\hline Triana-Los Remedios & 86.408 & 13.21 & 81.376 & 11.40 & 16.7 \\
\hline TOTAL & 653.972 & 100.00 & 713.404 & 100.00 & 100.0 \\
\hline
\end{tabular}

Fuente: Elaboración propia a partir de (*) Marchena, 1986, y (**) Boletín, 2004

\section{CUADRO 3.}

\section{CARACTERÍSTICAS DEMOGRÁFICAS}

\begin{tabular}{|l|r|c|c|c|c|}
\hline \multicolumn{1}{|c|}{ Distrito } & $\mathrm{H} / \mathrm{km}^{2}$ & $\begin{array}{c}\text { Indice } \\
\text { Vejez* }\end{array}$ & $\begin{array}{c}\text { Crecimiento } \\
\text { Vegetativo** }\end{array}$ & \% Extranjeros & $\begin{array}{c}\text { \% Estudios } \\
\text { Medios } \\
\text { sup*** }\end{array}$ \\
\hline Casco Antiguo & 14.209 & 1.8 & -0.3 & 1.9 & 38.2 \\
\hline Macarena & 3.700 & 0.9 & 1.8 & 0.7 & 16.3 \\
\hline Nervión- San Pablo & 13.872 & 1.3 & -1.2 & 0.5 & 32.2 \\
\hline Este & 4.618 & 0.6 & 5.6 & 0.5 & 14.0 \\
\hline Sur & 4.517 & 0.9 & 2.8 & 0.5 & 25.9 \\
\hline Triana- Los Remedios & 3.500 & 1.7 & -1.7 & 0.7 & 37.3 \\
\hline TOTAL & 4.987 & 1.0 & 1.8 & 0.7 & 24.2 \\
\hline
\end{tabular}

Fuente: Elaboración propia a partir del Boletín Demográfico, 2002

* Cociente entre la población mayor de 65 años y la menor de 15 . El del municipio es exactamente 0.976

** Diferencia natalidad mortalidad por cada 1.000 habitantes

*** Es el \% de los que poseen BUP, FP y Superior sobre la población total 
El cuadro anterior es significativo de las diferencias entre distritos para iniciar una investigación desglosada en unidades inferiores a los mismos, a fin de que la cartografía ayude a la caracterización y delimitación de las propuestas. La cantidad de población en relación a la superficie, se relaciona con el tipo de edificación, calidad de vida, espacios verdes y libres, hacinamiento; si bien no hay una ligazón simple densidad/rentas en general, sino que procede análisis de casos. En la tabla se aprecian fuertes disparidades, de manera que el índice de la Macarena (distrito con más de $40 \mathrm{Km}^{2}$ y una buena parte sin edificar) casi se multiplica por cuatro en el Casco histórico con pocos espacios vacíos, como también en Nervión.

El índice de vejez (importante, porque una población envejecida precisa más atención y unos servicios próximos) es en Sevilla prácticamente la unidad, pero entre distritos resulta ser el triple en el Casco histórico que en el Este. Por lo que también cabe esperar buenos resultados del uso de esta variable, así como del crecimiento vegetativo, cuya diferencia interdistrital supera los 7 puntos.

Menos obtendremos seguramente de los datos de la población inmigrada y extranjera (no necesariamente reales, como es sabido), con baja tasas en general y con pocas variaciones entre distritos, salvo, como suele ocurrir en otras ciudades, el centro histórico. Más expresivo será, sin duda, el nivel de instrucción, cuyas diferencias entre demarcaciones actuales es notable, y se trata de un índice que refleja bastante las características socioeconómicas.

\subsection{Transformaciones urbanas y proyectos}

Ciertamente las principales modificaciones en los últimos veinte años se refieren al crecimiento del área metropolitana, Aljarafe, Camas, Alcalá de Guadaíra, Dos Hermanas, sobre todo con urbanizaciones; es decir, en municipios distintos al de Sevilla. Pero desde la aprobación de los seis distritos actuales, la ciudad ha experimentado cambios urbanísticos y, más concretamente, expansión por algunos lugares, lo que explica las modificaciones demográficas y constituye una de las justificaciones de la propuesta que haremos. Lo más llamativo ha sido la transformación de la Cartuja y su entorno (gran cambio en Torneo, por ejemplo) de cara a 1992, que, aparte lo económico (menos, desde luego, de lo posible), ha supuesto la conquista de un espacio para la ciudad, ensanchando considerablemente el antiguo barrio de Triana, desde final de Castilla y el Patrocinio hacia el estadio olímpico y el parque del Alamillo, ya en los confines del municipio. Al igual que la SE-30, circunvalación, que mejora la circulación y aparece, a nuestro efectos, como un límite bastante claro en general.

En el Norte han surgido edificaciones por Nuevo Torneo, San Jerónimo, la parte sur y sureste de Pino Montano, en torno a Carrefour; Valdezorras, etc., que sin duda exigirán una ampliación del número de distritos. En el caso de Nervión-San Pablo, 
aunque la población no ha aumentado, las transformaciones internas han sido grandes; en buena parte por el soterramiento de la línea férrea, el cambio de función en la estación de San Bernardo y las repercusiones urbanas del entorno y, sobre todo, por la construcción de la nueva de Santa Justa y la urbanización de los alrededores (Calles Arroyo, José Laguillo...). Más al sur, la avenida y parque de la Buhaira, San Francisco Javier, zona de la Pirotecnia, Viapol, etc. Y, enfrente, el antiguo cuartel de Cuatro Vientos, hoy en edificación de viviendas, hoteles, Universidad, ya en el distrito Sur con un límite discutible.

Y en ese heterogéneo distrito más meridional ha habido transformaciones también (parques de Celestino Mutis y Prado de San Sebastián, unión Ronda Tamarguillo y Puente de las Delicias...) y una cierta expansión constructiva (Tiro Línea, Elcano, Los Bermejales y Bellavista) con ganancia de unos 6.000 habitantes en los últimos quince años. Sin embargo, es el extenso distrito Este el que más ha aumentado, cerca de cincuenta mil, reuniendo la cuarta parte de la población municipal. Su expansión se realiza sobre todo por la parte del Polígono Aeropuerto, donde en los últimos años se han construido bastantes urbanizaciones (Entreflores, Entreparques, Odisea, Camelias, Andalucía...).

Pero en este apartado, tan importante para avanzar en la investigación, es necesario tener muy en cuenta los proyectos y previsiones, como el PGOU 2002, aun considerando la posibilidad de cambios, como suele ocurrir. En este último Plan se considera una serie de proyectos de gran alcance hasta 2016 (El Prado, Santa Justa, Los Gordales, Tablada...), mira hacia su entorno, o Área Metropolitana, y se afianza como capitalidad de Andalucía en una consideración de multiplicidad escalar que escapa del habitual planeamiento interno.

Se pretende una potenciación ecológica y mayor integración de barrios y zonas periféricas, así como afianzar el concepto de ciudad mestiza con mezcla de usos (comerciales, residenciales, empresariales, culturales...), desplazamiento de polígonos industriales a la periferia y establecimiento de varios centros. Lejos de las planificaciones de zonas diferenciadas y de la ciudad dispersa norteamericana, lo que nos da un elemento más en la propuesta de delimitación distrital. Y como avance podemos resumir lo que sigue.

El Centro histórico no experimenta apenas modificaciones, si bien se afianza su carácter histórico y monumental con la rehabilitación de viviendas y peatonalización de calles, así como las mejoras en parques y jardines (el Valle, Parlamento, Murallas, Torneo...), que reforzarán la delimitación de la antigua Ronda.

En Triana-Los Remedios la construcción de nuevos puentes facilitará los enlaces, ahora congestionados, con el Aljarafe, con cuya comarca se establecerá un centro de transporte en el Parque de los Príncipes. Los Gordales (la feria de Abril se trasladaría al Charco de la Pava) se transformará con centros universitarios, áreas comerciales 
y de servicios. La antigua dehesa de Tablada constituye un amplio espacio bien situado, objeto de distintas apetencias e intereses (sobre todo ante la posibilidad para los actuales propietarios de construir 20.000 viviendas), pero el Avance del PGOU opta por crear un gran parque metropolitano en este lecho aun inundable del Guadalquivir.

La antigua isla de la Expo-92, también controvertible, se abrirá más a la ciudad, a la vez que se levantarán altos edificios de oficinas y comercios, aunque esta habiendo cierta contestación empresarial al incremento de edificabilidad. Pero, en cualquier caso, intensificación de un distrito, que ya por diversas razones aparece como demasiado extenso para seguir siendo una sola circunscripción.

En la zona norte de la Macarena hay amplios espacios, que se consideran en el PGOU más productivos y de transporte que de uso residencial; reducido éste prácticamente a la parte septentrional de San Jerónimo y Pino Montano, con urbanizaciones abiertas y rústicas, más la zona de Miraflores con unas 3.000 viviendas, entre el ferrocarril, el Tamarguillo y la conexión Santiponce-N IV. Se potencia el nudo de transporte de Majarabique con centros de mercancías y otras instalaciones, más nuevas edificaciones de Congresos y áreas productivas y empresariales entre las dos barriadas citadas, el nudo de la Gota de Leche y el Aeropuerto, sosteniendo parte del distrito aeronáutico. En la periferia, mantenimiento de suelo rústico, parques (Valdezorras, además de ampliaciones de Miraflores y del Norte), cinturón verde y, como decíamos, uso residencial extensivo. Así la realidad actual y los proyectos separan bastante el área norte del abigarrado mosaico de barrios de la Macarena entre las murallas y la SE-30.

Nervión-San Pablo se consolida como un gran espacio de servicios y transporte con una central metropolitana de autobuses junto a la estación de Santa Justa y la futura línea 2 del metro; quedando la del Prado para usos turísticos y la de Armas para líneas con el Aljarafe, junto con otra complementaria en los Príncipes. Se utilizarán los espacios y solares del Ayuntamiento y RENFE para construir torres y edificios emblemáticos, que transformarán la antigua barriada de la Calzada, la trasera de la estación y la zona José Laguillo-Samaniego. Por otro lado, desaparecerían los polígonos industriales, que pasan a la periferia.

En el Este continuará la expansión urbana (la ampliación del Polígono Aeropuerto suman más de 8.000 viviendas) hasta unir completamente Sevilla Este con Torreblanca, mejorándose la comunicación con Alcalá de Guadaíra (eje industrial) y sobre todo interna: se trasladará Mercasevilla al norte para integrar los desconectados barrios entorno con instalaciones nuevas de comercio y servicios y desaparecería el polígono industrial de Amate. A la vez que se crearía un espacio aeronáutico (San Nicolás-Sur del Aeropuerto con vocación de parque tecnológico, lo que orienta las construcciones) en relación con las pistas de aterrizaje y los proyectos de construcciones de aeronaves, que sería el gran motor industrial de la ciudad. 
En el Sur, además del desarrollo portuario, se pretende aprovechar amplios espacios de antiguos cuarteles, se dibuja un importante eje sanitario (hospitales Virgen del Rocío, Vigil de Quiñones y Valme más algunos centros y clínicas de la zona) y se construirán viviendas, ampliando Bellavista: Cortijo del Cuarto-Palmas Altas y polígono del Pítamo, con un total de casi 14.000 entre las dos zonas; se recupera el viejo cauce del Guadaíra y se amplía el parque. Otra función relevante será la de transporte, comunicando puerto y aeropuerto y enlazando mediante túnel con el Aljarafe. El actual límite ferroviario que aísla el Polígono Sur se soterrará entre Bami y Pineda y se prevén actuaciones de regeneración en los barios marginales de ese sector (aprobadas también en el Plan Estratégico), donde desaparece el polígono Navisa-El Refugio; y, en cambio, una especie de tecnópolis en Villanueva del Pítamo cerca de la Universidad Pablo de Olavide. O sea, proyectos de expansión y modificación de los distritos periféricos Norte, Este y Sur, muy a tener en cuenta en el trabajo para las propuestas de división y remodelación

\subsection{Aspectos económicos y sociales}

No disponemos de muchos datos publicados sobre este asunto, convenientemente desagregados por barrios, secciones u otras unidades inferiores al distrito, para poder detectar áreas homogéneas y acumular a las otras variables. Una muy importante es la declaración de renta, sintetizador de características económicas y sociales, pero las gestiones hasta ahora han sido infructuosas. Así que poco más vamos a poder utilizar que las licencias comerciales editadas en el Informe socioeconómico de la ciudad de Sevilla, 2002.

Ya se sabe que el número de dichas licencias enmascara diversidad de situaciones y que lo mismo cuenta una gran superficie que un pequeña tienda en el portal de una casa, pero sirve para comparar, que es de lo que se trata, máxime cuando aquí podemos distinguir entre comercio al por mayor y menor; y, sobre todo, porque en general las licencias de instalaciones más pequeñas suelen coincidir con zonas deprimidas. Pretendemos analizar la evolución del número de comercios y la situación de mayoristas y minoristas en cartografía desagregada inferior al distrito, ya que las diferencias de las actuales demarcaciones, según el cuadro siguiente, adelantan buenos resultados. 


\section{CUADRO 4.}

LICENCIAS COMERCIALES POR 1.000 HABITANTES EN EL 2002

\begin{tabular}{|l|c|c|c|c|}
\hline \multirow{2}{*}{\multicolumn{1}{c|}{ Distrito }} & \multirow{2}{*}{$\begin{array}{c}\text { Al por } \\
\text { mayor }\end{array}$} & \multicolumn{2}{c|}{ Comercio al por menor } & \multirow{2}{*}{ Total* } \\
\cline { 3 - 4 } & 2.9 & Alimentación & Industriales & \\
\hline Casco Antiguo & 2.2 & 3.7 & 29.2 & 39.7 \\
\hline Macarena & 4.0 & 3.2 & 5.4 & 11.7 \\
\hline Nervión-San Pablo & 1.1 & 2.7 & 8.4 & 16.5 \\
\hline Este & 1.9 & 3.0 & 4.8 & 9.3 \\
\hline Sur & 2.3 & 4.0 & 5.6 & 11.3 \\
\hline Triana-Los Remedios & & & 11.6 & 18.8 \\
\hline
\end{tabular}

Fuente: Elaboración propia a partir del Informe socioeconómico de la ciudad de Sevilla, 2002.

* La diferencia de este total y la suma de índices de las tres columnas se refieren a otras tres categorías que suponen en toda Sevilla para el año 2000 el $5.6 \%$, y que en cada distrito son tasas muy bajas. Por ejemplo, en el Este, 01,01 y 0.5 , respectivamente. Se trata de recuperación de productos, intermediarios de comercio y comercio mixto.

Por otro lado utilizaremos el reciente Plan General de Ordenación, cuya síntesis se publicó en diciembre del 2001, donde constan estrategias económicas, en relación sobre todo con la industria. La existencia de polígonos en la ciudad (Store, Calonge, Carretera Amarilla, Navisa...), aparte la caracterización paisajística y económica, marcan una parte de límites actuales y pueden ser objeto de modificaciones y traslados. A esos efectos nos interesa especialmente los siguientes:

— El de San Jerónimo focaliza un área al norte de Macarena

- Los polígonos Store y Calonge, de alto grado de consolidación, señalan una parte de la separación actual entre Macarena y Nervión.

— Igual ocurre con el sector Carretera Amarilla-San Pablo, que potencia el eje Avenida de Andalucía-Luis Montoto, a cuyas orillas de su prolongación oriental (sur de la de la carretera de Málaga) se localiza el Polígono del Pino.

- Así mismo el de Navisa linda con Avenida de Hytasa entre las actuales circunscripciones Este y Sur.

- La zona de la Dársena no añade nada como límite al eje fluvial, pero los proyectos culturales, recreativos y terciarios de esta zona trasladan hacia el sur unas actividades, que se diferenciarían del actual ya heterogéneo distrito Sur. 


\subsection{Instalaciones culturales y de participación ciudadana}

Se trata de tener en cuenta en este trabajo la distribución de una serie de elementos, cuya cartografía está publicada (CANO, Dir., 2002-b) y que son también significativos en el bloque de los criterios de caracterización, homogeneidad e incluso polarización. Es una buena fuente, porque las variables están localizadas por barrios y calles, si bien en este avance nos referiremos a la situación por distritos para igualar el formato con las otras variables que aún no hemos estudiado de forma desagregada. Las diferencias son muy acusadas, multiplicando el Casco antiguo (donde se localiza la mitad aproximadamente de las instalaciones en cada uno de los tipos) por 16 la tasa por mil habitantes de Macarena o el Este (cuadro 5). En los centros de participación la distribución es algo mejor, siendo ese multiplicador de 13 y la relación del Centro con los Remedios-Triana baja a cinco.

El patrimonio cultural y artístico se halla lógicamente en el Centro, sede de monumentos, palacios, iglesias, conventos, etc., resultado de un proceso histórico que no va más allá de la antigua ciudad amurallada, salvo iglesias con patrimonio y las bibliotecas universitarias. Y quizás la observación más significativa a efectos de límites es la continuidad de la parte meridional de Nervión hasta la SE-30 (mapa de las páginas 24 y 25 del Atlas citado).

\section{CUADRO 5.}

INSTALACIONES CULTURALES, SOCIALES Y PARTICIPATIVAS

\begin{tabular}{|c|c|c|c|c|c|c|c|}
\hline Distrito & $\begin{array}{l}\text { Patri- } \\
\text { monio }\end{array}$ & Difusión & $\begin{array}{l}\text { Partici- } \\
\text { pación }\end{array}$ & $\begin{array}{c}\text { Forma- } \\
\text { ción }\end{array}$ & $\begin{array}{l}\text { Adap- } \\
\text { tación }\end{array}$ & Total & $\begin{array}{c}\text { Total/ } \\
1.000 \mathrm{~h}\end{array}$ \\
\hline Casco Antiguo & 109 & 267 & 147 & 165 & 22 & 710 & 12.7 \\
\hline Macarena & 22 & 35 & 35 & 29 & 4 & 125 & 0.8 \\
\hline Nervión-San Pablo & 22 & 72 & 75 & 56 & 9 & 234 & 1.9 \\
\hline Este & 12 & 27 & 59 & 29 & 8 & 135 & 0.8 \\
\hline Sur & 30 & 54 & 56 & 28 & 14 & 182 & 1.6 \\
\hline Triana-Los Remedios & 22 & 89 & 43 & 41 & 6 & 201 & 2.5 \\
\hline TOTAL & 217 & 544 & 415 & 348 & 63 & 1.587 & 2.2 \\
\hline
\end{tabular}

En esa publicación se distinguen instalaciones con finalidades lucrativas (cines, teatros, cafeterías con actuaciones, videoclub, librerías...), pero con difusión y consumo cultural, de aquellas no comerciales, entre las que sobresalen los salones de actos de distintos centros e instituciones. Los mapas de las páginas 27-33 pueden indicar, aparte de la consolidación del Casco histórico en estos terrenos, la relativa 
importancia de barios periféricos como Pino Montano, Parque Alcosa y Bellavista (página 28-29) y la relevancia del sector septentrional del distrito Sur ligada a los centros universitarios.

Las instalaciones de participación, formación, creación y comunicación se refieren fundamentalmente a los centros de asociaciones (288), seguidos a distancia de las Hermandades de Semana Santa (cerca de cien), que señalan (aparte el Centro, la zona inmediata del Sur y los Remedios) una clara continuidad en el sector situado entre Luis Montoto-Andalucía y Ramón y Cajal hasta casi la SE-30.

También se distingue en el Atlas entre formación y creación (talleres artísticos, estudios fotográficos...) y medios de comunicación (imprentas, publicaciones, emisoras de radios...), notándose, sobre todo en éstos últimos, la parte meridional de Macarena y el vacío de Santa Clara-San Pablo dentro de Nervión. Las adaptaciones en la periferia de plazas, alamedas, parques, espacios deportivos, iglesias, etc. para actividades culturales contrapesa un poco la concentración de instalaciones del Casco histórico.

\subsection{Centros, ejes y comunicaciones}

Hasta aquí hemos visto criterios y métodos relativos a factores de expresión superficial en el sentido de urbanización y ocupación de espacios, población que aumenta o disminuye, instalaciones comerciales, sociales, culturales, etc., cuya expresión cartográfica sirve para caracterizar ámbitos y detectar discontinuidades, que ayuden a las delimitaciones. Es necesario introducir en los planteamientos de trabajo el criterio de funcionalidad, el más utilizado ahora en la singularización territorial, pero a escalas mayores de la municipal, comarcal y metropolitana sobre todo. Consiste en la localización de centros, generalmente ciudades grandes, que cuentan con importantes ofertas de bienes y servicios, públicos y privados, para abastecer a su población y también a núcleos circundantes; constituyendo precisamente un objeto de investigación averiguar cual es la zona de influencia de tal centro de ofertas. En la ubicación de éstas opera la economía de escalas, de forma que es necesario un determinado número de habitantes y de renta para mantener una Universidad, un hospital o una gran superficie comercial, por ejemplo.

A nivel municipal este criterio pierde mucho valor, porque las distancias no suelen justificar la multiplicidad de centralidades y, además, existe en general una acumulación de ofertas en los cascos históricos. Sin embargo, se están produciendo instalaciones comerciales y de ocio en zonas periféricas, donde hay cada vez más población, especialmente en urbanizaciones de tipo horizontal, menos congestión y más sitio de aparcamiento. Eso está pasando en Sevilla, más en el área metropolitana, Aljarafe principalmente, si bien emergen algunos nuevos centros y, aunque el casco histórico 
mantiene una gran parte de las ofertas, existe el propósito de aumentar los equipamientos de barrios y distritos para "garantizar un mínimo de calidad urbana en cada barrio" (OFICINA DEL PLAN, 2001, p. 79)

Conviene prestar atención en primer lugar a los servicios públicos (administración, sanidad, educación), sabiendo que tienden a ubicaciones centrales, si bien en Sevilla hay una cierta desconcentración en algunos barrios, desde luego no en las periferias, cuyo estudio puede colaborar a nuestros objetivos; y también servirá de orientación a la hora de localizar nuevas oficinas de la Juntas de distrito.

La administración mantiene muchas de sus instalaciones en el casco histórico, sobre todo la estatal más antigua, con fuerte presencia también en el distrito Sur, pero en la plaza de España, muy próxima al centro (delegación del Gobierno, varios Ministerios), aparte de algún pabellón de la Exposición de 1929 o en el parque de los Príncipes (oficinas del INEM en Blas Infante); si bien existen instancias de éstas o de Hacienda, por ejemplo, en otros barrios. La administración autonómica, más reciente, se localiza en Los Remedios (República Argentina), Torre Triana, la Cartuja; aunque también en el centro (Monsalves, Plaza de la Contratación, Santa María la Blanca) y proximidades (Palacio de San Telmo, sede de la Presidencia del Gobierno, Hospital de las Cinco Llagas, Parlamento andaluz), mientras los casos más alejados son raros (Consejerías de Trabajo y Asuntos Sociales en el Cerro del Águila, o Medio Ambiente en El Sur (Eritaña).

La sede principal del Ayuntamiento está en pleno centro, plaza Nueva, como suele ser habitual, pero el volumen de gestión ha ido desplazando oficinas dentro del casco histórico, o próximo a él (Plaza de América), y últimamente también en la Cartuja. Existen desde luego servicios descentralizados, como las propias sedes de los seis distritos, oficinas de asuntos sociales o policía local.

En la atención sanitaria se nota una cierta dispersión, incluso una acumulación en el distrito Sur, que, como dijimos, se tiende a aumentar en el PGOU con la formación de una especie de ciudad sanitaria y existen mapas de localización en la Consejería correspondiente. En este sentido no es preciso advertir que los datos mezclan instalaciones de diversa índole (el Hospital Virgen del Rocío, por ejemplo, cuenta como unidad en la tabla), características, origen, público, privado, concertado...Y, si nos fijamos sólo en los hospitales, destaca en segundo lugar la presencia del Clínico y de la Facultades de Medicina y Odontología en la Macarena, espacio tradicionalmente sanitario (las Cinco Llagas, San Lázaro). Los Remedios sobresale en las clínicas, por lo general de origen privado, mientras en Nervión-San Pablo se aprecia una buena distribución y en la suma queda en segundo lugar, como corresponde a un distrito de cierto nivel de vida. El Este es el caso contrario.

Los centros de enseñanza primaria no suelen generar desplazamientos apreciables, ni tampoco los de secundaria; si bien eso está cambiando cada vez más y uno de los integrantes de la congestión viaria a ciertas horas de los días laborables son precisamente los autobuses escolares. No obstante, a efectos de la centralidad que 
estamos apuntando, interesa la Universidad, cuya sede (con gran parte de los servicios generales más las Facultades de Derecho, Geografía e Historia y Filología) se sitúa en la antigua Fábrica de Tabacos en la calle San Fernando, distrito Sur, pero lindando con el casco histórico.

\section{CUADRO 6.}

\section{Equipamientos sanitarios}

\begin{tabular}{|c|c|c|c|c|c|c|c|}
\hline Distrito & $\begin{array}{c}\text { Ambula- } \\
\text { torios }\end{array}$ & $\begin{array}{l}\text { Centros } \\
\text { de Salud }\end{array}$ & Clínicas & $\begin{array}{c}\text { Consul- } \\
\text { torios }\end{array}$ & $\begin{array}{c}\text { Hos- } \\
\text { pitales }\end{array}$ & $\begin{array}{c}\text { Centros } \\
\text { Municipales }\end{array}$ & Total \\
\hline Casco Antiguo & 2 & & 2 & 3 & & 1 & 8 \\
\hline Macarena & 1 & 2 & & & 4 & 1 & 8 \\
\hline Nervión-San Pablo & 2 & 1 & 3 & 2 & 1 & 1 & 10 \\
\hline Este & 1 & 3 & & 1 & & 1 & 6 \\
\hline Sur & 1 & 3 & 5 & 2 & 9 & 1 & 21 \\
\hline Triana-Los Remedios & 1 & & 5 & 1 & 1 & 1 & 9 \\
\hline TOTAL & 8 & 9 & 15 & 9 & 15 & 6 & 62 \\
\hline
\end{tabular}

La Universidad de Sevilla está muy descentralizada y es un elemento que contribuye a crear ciertos núcleos de actividad educativa en distintos barrios, con lo que eso supone de comercios especializados, librerías, cafeterías, viviendas, etc. Su origen estuvo en pleno centro, donde aún queda alguna Facultad, Bellas Artes, en la calle Laraña. El distrito Sur debe mucho al campus de Reina Mercedes, donde se ubican principalmente las Ciencias y algunas Técnicas, luego del traslado de otras (Escuela de Ingenieros) a la Cartuja, donde se localiza también Ciencias de la Información. Macarena cuenta con el campus de la Salud y en Nervión se sitúan Económicas, Empresariales, Filosofía, Sicología, estando previsto el traslado de Derecho para formar el campus jurídico-económico; y en San Fernando, el área de Humanidades con las dos actuales ya mencionadas más Filosofía. Aún queda la Politécnica en los Remedios, en Ciudad Jardín parte de Pedagogía; e incluso la Escuela Agrícola en el campus de la nueva Universidad Pablo de Olavide, ya al final del término en el distrito Sur.

Existen otros servicios públicos menos indicadores de centralidad y, en cuanto a la empresa privada, su análisis nos llevaría muy lejos, pero sí conviene tener en cuenta a la hora de la investigación que el comercio, del que hablábamos en el apartado de indicadores homogéneos, se está desplazando del centro a la periferia y además con un modelo multioferta que engloba también restauración y ocio. Han surgido algunos en el centro, como el complejo de la antigua estación de plaza de Armas o Alcampo en el distrito Sur, pero ha prosperado sobre todo en Nervión con los Arcos, el Mirador y 
sobre todo Nervión Plaza, cerca del Corte Inglés. Esta empresa tiene previsto reforzar su presencia en ese distrito, Gran Plaza y Carlos V, si bien ésta última calle se ubica próxima al centro y al Cristina, donde se proyecta otra instalación, además de en República Argentina.

Menos interés tiene para nuestro estudio la distribución hotelera, de la que hay información; si bien es un elemento económico, turístico y de percepción por parte de los forasteros, aunque habría que profundizar en el tipo de visitantes, viajes, rutas organizadas y otras cuestiones que reforzaran o no esa percepción. En conexión con esto se halla la localización de Consulados y en el cuadro siguiente se nota la centralidad del casco histórico (donde están las principales oficinas de información), seguido del Sur (muchos consulados se instalan en antiguos pabellones de la Exposición de 1929) y Nervión, que, como estamos viendo, cada vez destaca más como un importante centro urbano.

Relacionado con lo anterior, se encuentran los principales nodos de transportes, que, además del Aeropuerto (en las afueras como en todos sitios), localiza también en Nervión la estación del AVE, mientras el apeadero de San Bernardo, en la línea con Cádiz, se sitúa en el Sur, aunque al lado de la Enramadilla. También una de las estaciones de Autobuses se ubica en el Prado, donde confluyen los distritos Centro, Nervión y Sur, mientras la nueva de Plaza de Armas refuerza el casco histórico, próximo a Triana.

CUADRO 7.

HOTELES DE 4 Y 5 ESTRELLAS Y CONSULADOS

\begin{tabular}{|l|c|c|c|}
\hline \multicolumn{1}{|c|}{ Distritos } & Hoteles & Consulados & Total \\
\hline Casco Antiguo & 5 & 17 & 22 \\
\hline Macarena & 1 & & 1 \\
\hline Nervión - San Pablo & 5 & 5 & 10 \\
\hline Este & 1 & & 16 \\
\hline Sur & 6 & 10 & 6 \\
\hline Triana - Los Remedios & 2 & 4 & 56 \\
\hline \multicolumn{1}{|c|}{ TOTAL } & 20 & 36 & 16 \\
\hline
\end{tabular}

Al elemento de polarización hay que unir los ejes, comunicaciones y transportes para completar el criterio funcional, si bien nos tememos la escasez de datos para un estudio más completo de esta variable. El parque automovilístico municipal no basta ante una avanzada formación de área metropolitana; los aforos de tráfico y los aparcamientos sí que arrojarán luz sobre centralidad y movilidad. Hemos sondeado ya la posibilidad de obtener más información sobre líneas de autobuses urbanos, 
principales puntos de terminales, trasbordos y rutas, circulares y radiales. Pero será mucho más complicado disponer en la duración acordada para este trabajo, de datos y su adecuada elaboración sobre tráfico, para dibujar flujos y detectar esas polarizaciones. Por supuesto que se tendrá en cuenta los proyectos del suburbano.

\section{ADAPTACIÓN DE LÍMITES}

Se han apuntado factores, criterios y métodos sobre superficies, posibles centros y líneas, que constituyen el armazón territorial, pero falta algo esencial: la delimitación más adecuada a la vista de las variables analizadas, de manera que las demarcaciones constituyen también objeto de sistematización desde el punto de vista geográfico, insistiendo en que no se trata de separar, sino, por el contrario, de enmarcar para mejorar la gestión y la participación. Como decíamos al principio, los límites abarcan multitud de espacios y tiempos, su tipología es amplia y tiene que ver con las escalas, de forma que en la municipal, la que ahora interesa, no suele haber grandes accidentes geográficos que separen. Y en el caso de Sevilla las alturas no van más allá de un cerro o las diferencias, ya atenuadas por la urbanización, de una llanura aluvial; en cambio los ríos sí que debemos considerarlos, el Guadalquivir en primer lugar, pero también los afluentes urbanos. Las líneas de ferrocarril siempre han sido verdaderos dogales para el crecimiento de las ciudades y claras fronteras, e incluso dejan a veces sus huellas tras los frecuentes soterramientos recientes. Y desde luego el viario (calles, avenidas, carreteras...) es el que al final marca la mayoría de los límites; cosa aceptada en muchas urbes.

\subsection{El Guadalquivir y sus afluentes}

Los ríos suelen separar y están con frecuencia en las ciudades porque a veces constituyen su propio origen, como sucede en Sevilla con el antiguo Betis, cuya importancia y permanencia como límite es indudable. Se trata del conjunto del Guadalquivir; el nuevo cauce occidental coincide con el término municipal y el brazo oriental (meandro de San Jerónimo, Canal de Alfonso XIII, dársena...) o "río" urbano ha servido como linde entre Sevilla y Triana, siendo respetado por todas las divisiones habidas (en la primera de 1863 aún no existía el canal).

No es necesario insistir mucho en la historia hídrica y en la obras (cortas, esclusas...) que marcan las dos orillas, aíslan y alejan a los ciudadanos (inundaciones, muros de defensa...), pero, por otro lado, no olvidemos la función portuaria, pasada y presente, de ocio y recreo, sobre todo con la habilitación (no aún del todo) 
de márgenes. Ni la reciente construcción de puentes, que, unidos a los ya existentes, constituyen una frecuente presencia: Alamillo, Barqueta, Cartuja, Cachorro, Triana, San Telmo, Los Remedios, Delicias y Centenario. Con todo, es una frontera muy clara (que no rompe barrios y deja al oeste el actual distrito Triana-Los Remedios), que probablemente se mantenga en las propuesta, sin perjuicio que esa parte occidental sea una circunscripción o más. No obstante el nuevo PGOU del 2002 prevé aumentar la comunicación entre ambas orillas mediante puentes, así como una mayor relación en el norte (la Cartuja-Casco histórico) y el sur (establecimiento de zona financiera, comercial y hotelera, tanto en la zona portuaria del Batán como en la Raza).

También algunos afluentes han tenido y tienen repercusiones; no tanto el Guadaíra, ya en el borde sur del término, aunque a mediados del XX aún delimitaba el barrio de Heliópolis en su antiguo camino hacia el río Grande por la zona del Batán. Desviado después, discurre por fuera de la SE-30, si bien separa más aún al barrio de Bellavista. El Tagarete entraba por la zona de Pino Montano y recorría norte-sur la parte de Miraflores-Calonge, girando al oeste para alcanzar una zona pantanosa, el prado de Santa Justa, y continuar paralelo a las murallas hasta bordearla por el lado del Alcázar y alcanzar el Guadalquivir por la Torre del Oro. Después se encauza desde el codo de Calonge hasta unirlo al Tamarguillo, quedando como lejano recuerdo poco más que el Parque de Miraflores.

El Tamarguillo, en cambio, ha tenido un mayor protagonismo y ha sido objeto de varias acciones de encauzamiento. Entraba desde el nordeste por la zona de la vereda de Poco Aceite (carretera Amarilla) y continuaba por donde actualmente está soterrado (ronda del Tamarguillo) hasta el cruce con Ramón y Cajal para desviarse al oeste y buscar al Guadalquivir (más o menos por las actuales General Merry- Felipe II- Eritaña) por el antiguo puente de Hierro. Después se desvió desde el mencionado cruce hasta lo que se denomina igualmente Ronda más o menos al llegar al parque Celestino Mutis para, ya en el polígono Sur, recorrer en sentido de los meridianos hasta el antiguo cauce del Guadaíra.

Su papel actual como divisoria de los distritos Nervión y Este deberá ser considerado, pues se trata de una ronda ancha con unos barrios al este (Los Pajaritos, Madre de Dios, Amate, Cerro del Águila...) bien distintos a los del oeste (Nervión, Ciudad Jardín), aunque ya sabemos que los límites no siempre son netos. Tendremos ocasión de valorar también el tramo, que, dentro del actual distrito Sur, va desde Ramón y Cajal al mencionado parque de Celestino Mutis, porque existen diferencias urbanas, sociales y económicas entre El Juncal y la barriada Felipe II, al oeste, y el polígono Hispalis y la Oliva, al este. Lo que no significa la búsqueda de demarcaciones homogéneas en características sociales, rentas y calidad de vida, como se dijo en el apartado conceptual. 


\subsection{El ferrocarril}

Las líneas férreas constituyen verdaderos dogales urbanos, cuyos trazados rompen a veces barrios tradicionales y, en cualquier caso, deterioran los entornos. La implantación de los tendidos férreos a finales el XIX viene a sustituir como frontera a las murallas medievales derribadas en algunas ciudades en 1868, cosa que ocurrió en Sevilla. Se instalaron dos estaciones, la de Córdoba y la de Cádiz, con tendidos que se unían al norte y sur fuera de la ciudad; desde la primera el muro de Torneo privó de la vista del río hasta 1992 y antes ya se había levantado los raíles que iban hacia el sur por el puerto.

En la fecha citada se construyó la nueva estación del AVE en Santa Justa (donde ya habían almacenes y aparcamientos), cambiando el paisaje urbano de la zona y soterrándose la línea hacia el sur hasta el cruce Ramón Carande-Bueno Monreal, a partir de donde se mantiene; primero bordeado con muros. Y, aunque hay un proyecto (POU, 2001) de continuar el soterramiento hasta la carretera Amarilla, actualmente constituye un claro límite que separa dos partes bien distintas en lo social, económico, urbanístico, etc. Como es, de un lado, Tabladilla, al sur del Porvenir, Hospital Virgen del Rocío y Bami y, de otro, el Polígono Sur con barrios tan marginados como las Tres Mil Viviendas.

En la parte norte, a espaldas de Santa Justa, hay una proliferación de vías que separan físicamente (no tanto desde otros puntos de vista, como en el sur) Fontanal, Árbol Gordo y la Corza del barrio de las Huertas alargado a orillas de la avenida Kansas City. Y, aunque la principal arteria de unión, Avenida Manuel del Valle, dispone de un paso elevado, estamos en una zona de difícil delimitación, porque cerca, al oeste, se encuentra la ronda María Auxiliadora y, muy próximo, el eje hacia el Aeropuerto. Menos importancia tiene a nuestros efectos la separación que introduce el ferrocarril más al norte entre los polígonos Store y Calonge para enlazar con el ramal norte-sur más allá de la SE-30.

Hay una línea oriental periférica entre ese nudo septentrional, en la ronda Supranorte junto al encauzamiento del Tamarguillo, y la unión meridional en Bellavista con el tendido que va a Cádiz. Se pretende utilizar como servicio de cercanías con apeaderos en el citado barrio sur, El Pítamo, Universidad Pablo de Olavide, Palmete, Palacio de Congresos, Feria de Muestras, Pino Montano y estación de mercancías de Majarabique o nudo norte.

Y, por lo que ahora interesa, ciertamente separa urbanizaciones de Sevilla Este (Continente, Puerta Este) de Parque Alcosa y el Palacio de Congresos, pero es una zona homogénea en muchos aspectos. Al sur discurre paralelo al encauzamiento del arroyo Ranilla por la estación de la Negrilla separando una zona menos poblada entre polígonos industriales y algunos barrios; el de Padre Pío, roto por el tendido. Aunque se estudiará detenidamente, este límite está demasiado cercano a la SE-30 que, en todo caso en principio sería más definitivo. 


\subsection{El viario}

El viario (calle, avenidas, carreteras...) es el que al final marca la mayoría de los límites y así aparece en la división actual (Carretera de Carmona-autopista de San Pablo, Av. Andalucía-carretera de Málaga y Ramón y Cajal-Av. de Hitasa...) y también en otras ciudades; por ejemplo Córdoba, para cuyos distritos escribe MULERO, 1988: "Utilizan como límites a las principales vías de comunicación y acceso a la ciudad, lo que resulta un criterio acertado, ya que las grandes arterias circulatorias desagregan el espacio urbano, otorgando a cada fragmento una singularidad que es normalmente sentida por los propios habitantes" (p. 112).

Y además de las grandes arterias otras vías actúan como divisorias, aunque no se puede generalizar en absoluto, ni siquiera en todos los tramos de una misma calle, de forma que unas distancian y otras integran y no siempre en función de la anchura. No cabe duda que la Ronda del Tamarguillo, límite actual de Distritos en una parte, separa distintas situaciones socioeconómicas y urbanísticas. Sin embargo, otras vías amplias del distrito Este no diferencian, a la vez que, por ejemplo, la calle San Fernando, entre los distritos centro y sur, no es frontera para los universitarios de la antigua fábrica de Tabacos. La delimitación, pues, debe ser resultado de múltiples criterios; en realidad de todos los que estamos utilizando, pero materializados en unos elementos concretos, sin olvidar que sólo son marcos para una mejor administración y que deben ser en lo posible líneas claras de referencia.

\subsection{La ronda histórica}

La ronda es un límite mantenido en las distintas divisiones (salvo la del siglo XIX, en vísperas de la destrucción de la muralla), aunque con algún matiz en el borde suroriental. El distrito actual enlaza Puerta de Jerez con el Puente de San Telmo, un poco más al sur que el trazado islámico, que seguía el Tagarete (San FernandoAlmirante Lobo) hasta su desembocadura cerca de la Torre del Oro. Pero no es la única discordancia con la ronda de la ciudad andalusí, porque entre la muralla y el río estaban los barrios del Arenal y los Humeros, aunque, lógicamente no se va a separar en un distrito esa estrecha banda hasta el río.

En el nordeste, entre la muralla y la actual ronda, estaba la antigua fábrica de Salitre, hoy Jardines del Valle y un poco más al sur queda entre el muro (calle de los Navarros) y la calle Recaredo una parte del barrio de San Roque; y al sureste también estaba adosada la antigua Huerta del Retiro, ahora Jardines de Murillo. Es decir, que la Ronda actual no es en todo su recorrido la parte exterior de la muralla islámica, pero sí en su mayoría y creemos que dicha circunvalación tiene suficiente antigüedad y aceptación como para mantener este límite; aunque, ya lo sabemos, no en todo 
su recorrido, más bien en ninguno, sea una frontera (no olvidemos que los límites entre distritos no son muros).

No obstante, interesa ver posibles alternativas, porque algunas transformaciones hacen menos clara la separación. Así al norte (edificios en Nueva Torneo, Facultad de Odontología, desaparición de chabolas, Parlamento andaluz) aumenta la conexión entre ambos lados, si bien estamos precisamente en el lienzo conservado de muralla. Tampoco es una frontera insalvable la calle María Auxiliadora, pero marca más que la del Sol, si quisiéramos ser estrictos con el trazado almohade. Y lo mismo cabe decir entre Los Navarros y Recaredo, aunque la propuesta de MORENO, 2001 (llevando el límite hasta las soterradas líneas de ferrocarril reunificando el antiguo Barrio de San Roque) debe estudiarse, sin olvidar lo que supone de aceptación generalizada el límite actual.

Los Jardines de Murillo, no posibilitan un trazado diferente y, como dijimos, la calle San Fernando no es hoy la separación del antiguo Tagarete y entre el edificio central de la Universidad y de los servicios de enfrente (dependencias universitarias, cafetería, librerías...) hay un constante trasiego, por lo que aquí podría haber una excepción, quizás con el Palacio de San Telmo. Si bien, recordemos el sentido de estos límites y, también que al tener contenidos de participación, conviene considerar que los usuarios universitarios o representantes políticos son en realidad vecinos de otros lugares del municipio, pueblo o urbe distinta.

\subsection{La circunvalación. La SE-30}

Esta vía rápida de 1992 forma un anillo, especie de muralla, más al exterior, ampliando la delimitación del plano de manera circular, al igual que las antiguas rondas. Pero de una manera más dura, tanto por la anchura, como, y sobre todo, por la rapidez del tráfico y la ausencia de pasos peatonales o semáforos, si bien en algunos lugares hay pasos elevados. Con todo no es un sistema tan rígido ni tan deteriorante del paisaje urbano como el ferrocarril y habrá que estudiar bien cada uno de los tramos y su posible incidencia en los nuevos límites.

Al estar ya bastante saturada, se está planteando desde el PGOU su integración en la ciudad con soterramiento de hasta cuatro tramos, y desplazar tráfico hacia un nuevo eje al Este (la SE-35), además de la proyectada circunvalación metropolitana o SE-40. Pero, de momento constituye un límite muy considerable y es de suponer que, aun integrada en un futuro, divida espacios y haya creado unas condiciones y costumbres de separación. Habrá que ver detenidamente su trazado y cómo puede repercutir en la división de distritos; ahora, sólo una primera aproximación.

La entrada por el noroeste (entre el nuevo cauce del Guadalquivir y el meandro de San Jerónimo por el puente del Alamillo) discurre por una zona no residencial, (parque, aparcamientos...), sin efectos a nuestros propósitos. Hacia el este es más 
bien una vía urbana hasta por lo menos el Parque Norte (antes Vacie), no obstante la separación en toda esta zona parece clara. En el ángulo nordeste bordea perfectamente los polígonos industriales de Store y Calonge hasta el Nudo de la Gota de Leche, donde conecta con la N-IV. En el largo recorrido oriental (casi paralelo a la línea del ferrocarril Madrid-Cádiz de más al este) forma a menudo un límite claro, a veces por usos distintos (industria-servicios/residencias) o características socioeconómicas.

Después se establecen diferencias (menos socioeconómicas que de fechas de construcción y estructuras) entre la Ciudad Jardín de Santa Clara, a un lado, y las urbanizaciones de Sevilla Este, a otro (Cuatro Torres, Jardín del Este, Moraleja...). Más marcadas quedan las dos orilla de la SE-30 hasta la carretera Amarilla con el polígono de este nombre, al oeste, y otras promociones al Este (Las Azores, Las Góndolas...). También son evidentes las diferencias a ambos lados de este límite de la circunvalación desde la Avenida de Andalucía hasta el codo que gira al oeste: a una parte Santa Aurelia, Parque Amate, Juan XXIII y la Plata y, a la otra, pocas instalaciones, (estación de la Negrilla, barrio del Padre Pío, lindando ya con el municipio de Alcalá de Guadaíra) como para crear una fuerte división. En el enlace con la carretera de Utrera hay también planes ligados, entre otras cosas, al parque del Guadaíra y en la parte sur y oeste (Elcano, Tablada, los Remedios y Charco de la Pava). Pero ya por la zona meridional y occidental la SE-30 discurre próxima al límite municipal.

\subsection{Ejes radiales}

En Sevilla, como otras ciudades andaluzas amuralladas los ejes radiales son muy importantes porque constituyen frecuentemente antiguos caminos ligados a puertas de la cerca. Uno de ellos es la carretera de Carmona, que separa hoy los distritos norte, por un lado, y Nervión-San Pablo/Este, por otro, constituyendo un eje antiguo de la ciudad, muy consolidado entre espacios distintos a ambos lados; antes huertas, hoy barrios. Salía de la medieval Puerta del Sol y dejaba al norte, además de la laguna de los Patos, las huertas de Pajarito, San Francisco, Cisne Bajo y Cisne Alto hasta llegar al cortijo de Calonge, pasado el Tagarete y, antes, una zona de secano y olivar. Al sur quedaban otras huertas, hoy barrios: Trinidad, Fontanal, Santa Marina y Árbol Gordo.

A mediados del XIX todo esto estaba sin edificar y un siglo después se mezclan huertas y barrios: Fontanar (mantenemos los cambios toponímicos), Árbol Gordo, la Corza. Al este del cruce con el Tagarete no había nada, pero hoy ese eje separa barrios distintos con claridad: al norte los polígonos de Store y Calonge y una zona sin edificar al este de la SE-30 (excepto alguna barriada, como Aeropuerto Viejo, lejos de la vía en cuestión, y poco más). Al sur, la ciudad jardín de Santa Clara y 
al este, nuevas urbanizaciones (Cuatro Torres, Alhami, Jardines el Edén...) y el Parque Alcosa. Estamos, pues, ante un eje delimitador bastante claro y antiguo.

Otras vías septentrionales no menos pretéritas separan barrios, pero no distritos en ninguna fecha, dado que no encierran espacios suficientes para tales demarcaciones. Citemos al menos tres de este a oeste. Primero el camino de Cantillana, hoy Avenida Doctor Fedriani-Carretera Alcalá del Río, que sale de la puerta Macarena, dejando a la izquierda el Hospital de las Cinco Llagas y, más arriba, el de San Lázaro; en medio, sólo huertas a mediados del XIX, hoy barrios, como Palmilla o El Cerezo. Segundo, el Camino del Gordillo, hoy avenida de la Cruz Roja, con huertas antecedentes de barrios (Capuchinos, Barzola, Hierro). Y, en tercer lugar, también entre huertas, el camino de Miraflores, hasta la hacienda del mismo nombre, con una bifurcación hacia el cortijo de Pino Montano, origen de la actual barriada.

En el este hay que detenerse bien en las antiguas calle de Oriente y Camino de Alcalá. Desde la antigua Puerta de Carmona salía un camino hacia esa población, denominado hoy Luis Montoto, Avenida de Andalucía y carretera de Málaga, que constituye un importante eje transversal este-oeste. Separaba tradicionalmente huertas próximas a la ciudad amurallada y ha dado origen a barrios (Calzada, significativo topónimo, San Benito, El Pilar, Santa Teresa...), que desde la ermita Cruz del Campo se intercalaban entre el secano y el olivar, si bien algunos de esos regadíos se han convertido también en barrios: Ranilla (donde hoy el Polígono carretera Amarilla), Candelaria o Amate.

En 1863 separaba los distritos II y X, pero en la reforma de 1970 la parte más cercana a la ciudad cambia la divisoria desde Cruz Campo por Greco y la zona de Santa Justa. En la reforma de 1989 el tramo desde Puerta de Carmona a Ronda del Tamarguillo no es un límite, sino que constituye el eje central del distrito Nervión-San Pablo y realmente no sería muy adecuado establecer una separación entre Santa Justa y los Lebreros o el Corte Inglés. De la citada ronda a la SE-30 forma límite de dos distritos, no así hacia el este, cuestión que estudiaremos cuidadosamente.

El antiguo camino de Alcalá, y hacienda de Quinto, desde la Puerta de San Fernando (hoy Enramadilla, Ramón y Cajal, Avenida Hytasa) es otro eje delimitador, que funciona desde los distritos de 1970 hasta hoy. No era una zona de huertas tan densas como otras del entorno urbano (Florindo, Cortijo de la Cera...), tanto por las zonas húmedas provocadas por el Tamarguillo (Juncal, San Sebastián) como por un cierto desnivel del Cerro del Aguila.

Aunque los límites en general son a veces artificiales y responden a necesidades de administración y gestión, en este caso el eje diferencia poco y más bien es integrador en parte de su recorrido. Tal ocurre con la calle San Fernando o la avenida de Carlos V; más aún en la Enramadilla con la Facultad de Económicas a un lado y la futura de Derecho a otro. La separación sí se acusa al este entre Ciudad Jardín y el Plantinar- Juncal y, en principio, en Avenida de Hytasa, si bien la distinción entre el Cerro del Águila y la zona industrial que lo originó es discutible. 
De los ejes meridionales, el más antiguo es la carretera de Dos Hermanas (parte de la Avenida de la Borbolla-Manuel Siurot), muy mediatizado por la avenida de la Palmera, vía de la Exposición de 1929, demasiados cercanos a la Dársena como para erigirse en límites de distrito. Más obstáculo ha sido, como vimos, el ferrocarril.

\subsection{Otras vías}

En esta metodología habrá que estudiar también otras posibilidades, aunque no existen muchas más vías transversales en una ciudad, como tantas otras, de casco histórico amurallado con puertas y caminos radiales. No obstante, pueden citarse algunos ejes modernos, como Dr. Marañón-Pío XII en la Macarena; Luis MoralesSan Francisco Javier y Cruz Campo-Ciudad Jardín en Nervión; Merry-Felipe II o las prolongaciones de Tamarguillo en el distrito Sur; la arteria que va del Patrocinio a Tablada (López de Gomara-Virgen de la Oliva) en Triana.

\subsection{Las comunicaciones y el Área Metropolitana}

La expansión de edificaciones, en buena parte urbanizaciones, más allá del municipio de Sevilla, y las consiguientes infraestructuras de comunicaciones y servicios están consolidando un territorio que excede el término capitalino, donde radica, de todas formas, la centralidad. Se trata de un área metropolitana, que, sin llegar a la importancia de otras urbes mayores (Barcelona, Madrid) o similares (Valencia), requiere una nueva organización, en la que están empeñadas distintas administraciones locales y autonómicas, aunque no es tarea fácil. Pero la metropolización de algunos servicios, transportes y comunicaciones es necesaria y existen proyectos de metro, autobuses, circunvalaciones, etc. en orden a esa consecución. A los efectos que aquí se persiguen, la consideración metropolitana no puede ir mucho más allá de procurar la apertura de distritos hacia la periferia, si bien, como es lógico, siempre habrá algunos interiores, como el Centro o Nervión.

\section{LAS PROPUESTAS DE NUEVOS DISTRITOS}

No se trata ahora de hacer la propuesta antes del análisis, sino de disponer de una metodología para presentar las modificaciones de distritos; $y$, aunque una parte de la misma irá surgiendo con el trabajo, algunas cosas sí pueden preverse. En primer lugar, partir de los distritos actuales y en cada uno de ellos aplicar los factores y criterios señalados para deducir si conviene subdividirlo y con qué límites internos, 
así como la posible modificación de los actuales. Esto es, no partir de cero, pero sin dejar de considerar todas la posibilidades que podrían en algún caso hacer desaparecer o desfigurar una demarcación actual. Todo ello pensando en lo más adecuado a los fines propuestos y no en realizar una parcelación en terreno ignoto.

Otra cuestión es evitar hacer propuestas rígidas, sino que, cuando haya dudas (y en los estudios de territorializaciones casi siempre las hay), se plantearán varias alternativas; las necesarias para que no se convierta en un trabajo realmente inútil por la cantidad de posibilidades. Podría decirse que en cada distrito actual las propuestas serían de una a tres. Indudablemente todas tendrá que estar suficientemente motivada con las ventajas e inconvenientes y, también, apuntando un balance de cual parece mejor.

Dada la cantidad de variables a utilizar, dichas propuestas no deben seguir un esquema uniforme, sino que conviene remarcar en el índice qué factores y elementos predominan en las mismas. Parece mejor intentar denominar los nuevos distritos, manteniendo ya los nombre existentes; por ejemplo, si en el de Macarena hubiera que delimitar otro, quedaría esa denominación para el más próximo al centro, buscándose otra para la periferia (San Jerónimo, Pino Montano...), lo que de algún modo obligará a nombres compuestos a fin de recoger los barrios más significativos. Y, por último de momento, es imprescindible presentar una delimitación clara con el callejero y la correspondiente cartografía, a fin de facilitar la toma de decisiones y componer el obligado mapa distrital sin ninguna confusión.

\section{BIBLIOGRAFÍA}

ALMOGUERA SALLENT, P.: El Área de Sevilla como sistema metropolitano, Sevilla, I.D.R., 1986, 467 pp.

AYUNTAMIENTO DE SEVILLA: Anuarios estadístico municipales, varios años

AYUNTAMIENTO DE SEVILLA: Boletín demográfico de la ciudad de Sevilla, varios años. El último, publicado en el 2002, contiene datos del año anterior.

AYUNTAMIENTO DE SEVILLA: Informe socioeconómico de la ciudad de Sevilla, 2000

CANO GARCÍA, G.: Aproximaciones al Análisis Geográfico Regional, Sevilla, Servicio de Publicaciones de la Universidad, 1985

CANO GARCÍA, G.: "Metodología para delimitar y caracterizar espacios homogéneos", en Cano (Dir.): Geografía de Andalucía, Sevilla, Ed. Tartessos, 1987-90, tomo octavo

CANO GARCÍA (Director): Las Comarcas andaluzas, Sevilla, Ed. Tartessos, 2002-a, 455 pp.

CANO GARCÍA (Director): Atlas Cultural del Municipio de Sevilla, Sevilla, Área Cultura Ayuntamiento y Universidad, 2002-b

Expediente instruido para la división del término Municipal de Sevilla en barrios, 1992 
GRANIER, L.: "La organización territorial y la descentralización administrativa en París”, Juntas de Distrito, Jornadas, 1997, Madrid, Ayuntamiento, 858 pp.

HUERTA RICO, A. M.: “Competencias y servicios de las Juntas Municipales de Distritos. Estructura y organización. Coordinación interna y externa”, Juntas de Distrito, Jornadas, 1997, Madrid, Ayuntamiento,

MARCHENA GÓMEZ, M. y LÓPEZ LARA, E. Propuesta para la nueva división territorial del término municipal de Sevilla, Área de Participación Ciudadana, 1988

MARTÍN GARCÍA, A.: Sevilla (1872-1994), Ciudad y territorio, Sevilla, Fundación Colegio Aparejadores y Arquitectos Técnicos, 1996, 441 pp.

MORENO NAVARRO, I. (Director): Informe-Diagnóstico final. Propuesta de nueva organización territorial de la ciudad de Sevilla, Sevilla, 2001

MULERO MENDIGORRI, A.: "las divisiones territoriales en la ciudad de Córdoba", Revista de Estudios Andaluces, $\mathrm{n}^{\circ}$ 11, 1988, pp. 109-136

OFICINA DEL PLAN DE SEVILLA (Gerencia de Urbanismo): Síntesis del Documento para Ordenación Urbana-Territorial de Sevilla, 2001

RIVERO YSERN, J.M.: Manual de Derecho Local, Madrid, Civitas, 2000, Cuarta Edición.

SCHMIALEK, M.: “Berlín. La transformación de una ciudad y su administración”, Juntas de Distrito, Jornadas , 1997, Madrid, Ayuntamiento, 858 pp. 